\title{
Blood haemoglobin concentrations are higher in smokers and heavy alcohol consumers than in non-smokers and abstainers - should we adjust the reference range?
}

\author{
Nils Milman • Agnes N. Pedersen
}

Received: 2 July 2008 / Accepted: 11 November 2008 /Published online: 29 November 2008

(C) Springer-Verlag 2008

\begin{abstract}
The blood haemoglobin concentration is one of the most frequently used laboratory parameters in clinical practice. There is evidence that haemoglobin levels are influenced by tobacco smoking. The objective of this study was to evaluate the impact of smoking and alcohol consumption on haemoglobin concentrations in apparently healthy subjects living at sea level. A retrospective, epidemiological cohort study was performed in 1984. Participants were 1,503 men and 1,437 non-pregnant women evenly distributed in age cohorts of $30,40,50$, and 60 years. Information of smoking habits and alcohol consumption were obtained by a questionnaire. Haemoglobin was measured in the fasting state on Coulter-S. Men displayed no difference in mean haemoglobin levels in the four age groups. In women, mean haemoglobin increased gradually with age $(p=0.001)$. Fifty-nine percent of men and $50 \%$ of women were daily smokers. Female smokers displayed a significant positive correlation between number of cigarettes/day and haemoglobin concentrations $(r=0.12$, $p=0.002$ ). Heavy smokers (more than ten cigarettes/day)
\end{abstract}

\section{N. Milman}

Department of Clinical Biochemistry, Næstved Hospital,

Næstved, Denmark

N. Milman

Research Centre for Prevention and Health,

Copenhagen Region, Glostrup, Denmark

A. N. Pedersen

Department of Nutrition, National Food Institute,

Technical University of Denmark,

Copenhagen, Denmark

N. Milman $(\bowtie)$

Lindevangen $87 \mathrm{~B}$,

2830 Virum, Denmark

e-mail: nils.mil@dadlnet.dk had significantly higher mean haemoglobin (1.4\% higher in men, on average $3.5 \%$ higher in women) than non-smokers $(p<0.01)$. Smokers demonstrated a significant correlation between cigarettes/day and drinks/week in men $(r=0.24$, $p<0.001)$ and women $(r=0.16, p<0.001)$. Non-smokers displayed a significant positive correlation between drinks/ week and haemoglobin concentrations in men $(r=0.14, p=$ $0.001)$ and women $(r=0.08, p=0.05)$. In non-smokers, alcohol consumption $>14$ drinks/week and more than seven drinks/week for men and women, respectively, increased mean haemoglobin by $1.3 \%$ in men and by average $1.9 \%$ in women compared with those consuming $\leq 14$ and less than or equal to seven drinks/week. Smokers displayed similar results. Body mass index per se had no direct influence on haemoglobin levels but had indirect positive influence in men through its correlation with tobacco smoking and alcohol consumption. Tobacco smoking has an increasing effect on haemoglobin concentrations in both genders, which is proportional to the amount of tobacco smoked. The effect appears to be more pronounced in women. Likewise, high alcohol consumption has an increasing effect on haemoglobin in both genders, being most pronounced in women. However, in clinical biochemistry, the relatively small changes in haemoglobin do not justify the use of separate reference ranges in smokers and alcohol consumers.

Keywords Alcohol · Body mass index .

Epidemiological study $\cdot$ Ferritin $\cdot$ Hemoglobins $\cdot$ Men ·

Reference range $\cdot$ Smoking $\cdot$ Women

The blood haemoglobin concentration is one of the most frequently used laboratory parameters in the clinical routine, and it is a key variable in the assessment of health 
status and in the discrimination between healthiness and disease $[1,2]$. In epidemiological studies, low and high haemoglobin levels, even within the reference range, are predictors of mortality [1, 2]. The establishment of appropriate reference ranges in healthy populations is therefore of paramount importance [3].

In previous papers we have described iron status and the distribution of haemoglobin concentrations in apparently healthy Danes $[4,5]$ but not considered the potential influence of smoking. However, in our recent paper on 80-year-old subjects [2], it appeared that tobacco smoking had a significant influence on haemoglobin levels, i.e. smokers displayed higher levels than non-smokers. Search of the literature disclosed several papers reporting an association between smoking and haemoglobin [2, 3, 68], although the studies were not specifically designed to evaluate this topic. The widespread and variable habit of smoking makes it a potential confounder in the establishment of normal reference ranges for haemoglobin. The objectives of the present study were to clarify the influence of smoking habits, alcohol consumption and, in addition, body mass index on haemoglobin concentrations and to define reference ranges for non-smokers in a cohort of apparently healthy Danes.

\section{Materials and methods}

\section{Subjects}

The selection of the participants has been described in detail elsewhere [4, 5]. During 1982-1984, a World Health Organization-initiated study, Monitoring of Trends and Determinants in Cardiovascular Disease (DAN-MONICA1) was performed at the Center for Population Studies in Glostrup, Denmark. The participants were residents in Greater Copenhagen and lived at sea level. A randomised sample of 2,404 men (124 of non-Danish origin) and 2,403 women (103 of non-Danish origin) in age cohorts of 30, 40, 50 , and 60 years was derived from the Census Registry and were invited by letter to a health examination. A total of 1,843 men (77\%) accepted the invitation and were examined in November 1982 through January 1984; among these, 1,503 men examined in February 1983 through January 1984 participated in the iron status survey (70 of non-Danish origin). A total of 1,765 women (74\%) accepted the invitation, and 1,455 women examined in February 1983 through January 1984 participated in the iron status survey. After exclusion of pregnant women ( $n=$ 18 ), the final series comprised 1,437 non-pregnant women (78 of non-Danish origin).

Concerning demographic characteristics, the population sample was representative for the entire Danish population, except that farming and fishing occupations were slightly underrepresented.

Methods

All participants had a clinical examination and gave a detailed medical history including blood donation activity and menopausal status. Tobacco smoking was assessed in a questionnaire containing questions about the frequency of smoking and the quantity of tobacco being smoked. "Heavy smokers" were defined as those whose smoke more than ten cigarettes/day. Alcohol consumption was likewise assessed in a questionnaire and transformed into drinks per week. A drink contains $\sim 12$ g ethanol. "Heavy drinkers" were defined as those who consume $>14$ drinks/ week for men and more than seven drinks/week for women according to the Nordic recommendations [9]. Body mass index (BMI) was calculated as body weight in kilogram divided by body height in square meters.

Blood samples were drawn in the fasting state between 0800 and 1100 hours. Venipuncture was performed with the participants seated in a recumbent position and using a minimum of compression on the upper arm. Haemoglobin $\mathrm{Hb}$ ) was measured on Coulter-S. In order to convert from $\mathrm{Hb}$ in $\mathrm{mmol} / \mathrm{L}$ to $\mathrm{Hb}$ in $\mathrm{g} / \mathrm{L}$, the value multiply by 0.06205 . Serum ferritin was measured by an immunoradiometric assay (Phadebas Ferritin PRIST ${ }^{\circledR}$, Pharmacia Diagnostics, Uppsala, Sweden) [10]. According to the results obtained in our previous studies $[2,3]$ we considered serum ferritin values $>20 \mu \mathrm{g} / \mathrm{l}$ to be consistent with the absence of iron deficiency anaemia.

\section{Statistics}

Haemoglobin values and serum ferritin $\log _{10}$ values displayed normal distributions. Differences between groups were assessed by Pearson's chi-square test, analysis of variance (ANOVA) and Student's two-tailed $t$ test for unpaired observations. Correlations were assessed by Pearson's coefficient of correlation $(r)$. Reference ranges were calculated as $95 \%$ confidence intervals $(\mathrm{CI})=$ mean \pm (1.96SD).

\section{Results}

Tobacco smoking

The number of participants in the various age cohorts and smoking groups are shown in Table 1. Among men, 59\% $(n=892)$ were daily smokers, and the smoking pattern was fairly similar within the age groups. Among women, 50\% 
Table 1 Smoking habits of the participants in the study

\begin{tabular}{|c|c|c|c|c|c|}
\hline & \multirow[t]{2}{*}{ Number of subjects } & \multicolumn{3}{|l|}{ Smoking } & \multirow[t]{2}{*}{$p$ value $^{\mathrm{a}}$} \\
\hline & & Daily, $n(\%)$ & Occasionally, $n(\%)$ & No, $n(\%)$ & \\
\hline \multicolumn{6}{|l|}{ Men } \\
\hline \multicolumn{6}{|c|}{ Age (years) } \\
\hline 30 & 380 & $230(61)$ & $16(4)$ & $134(35)$ & \multirow{5}{*}{0.4} \\
\hline 40 & 388 & $227(59)$ & $16(4)$ & $145(37)$ & \\
\hline 50 & 381 & $237(62)$ & $8(2)$ & $136(36)$ & \\
\hline 60 & 354 & $198(56)$ & $11(3)$ & $145(41)$ & \\
\hline Total & 1,503 & $892(59)$ & $51(4)$ & $560(37)$ & \\
\hline \multicolumn{6}{|c|}{ Women } \\
\hline \multicolumn{6}{|c|}{ Age (years) } \\
\hline 30 & 381 & $223(58)$ & $10(3)$ & $148(39)$ & \multirow{5}{*}{0.0001} \\
\hline 40 & 375 & $169(45)$ & $16(4)$ & $190(51)$ & \\
\hline 50 & 357 & $196(55)$ & $12(3)$ & $149(42)$ & \\
\hline 60 & 324 & $128(40)$ & $16(5)$ & $180(55)$ & \\
\hline Total & 1,437 & $716(50)$ & $54(4)$ & $667(46)$ & \\
\hline
\end{tabular}

${ }^{\text {a }}$ Pearson's chi-square test

$(n=716)$ were daily smokers, and there were significant differences between the smoking pattern in the age groups, those being 30 years of age having the highest and those being 60 years of age the lowest frequency of smoking $(p<0.001)$.

Among daily smokers $(n=1,608), 710$ men $(80 \%)$ and 670 women (94\%) smoked cigarettes. Among men, 203/ $710(29 \%)$ and among women 250/670 (37\%) smoked less than or equal to ten cigarettes/day $(p=0.0001)$.

\section{Alcohol consumption}

Only 49 men and 169 women neither smoked nor drank alcohol. Among men, 1,388 (93\%) consumed alcohol (missing information in 2), mean 14 drinks/week, median nine drinks/week (observed range, 1-170); 317 (23\%) consumed $>20$ drinks/week. Among women, 1,122 (78\%) consumed alcohol (missing information in 1), mean six drinks/week, median three drinks/week (observed range, 170); 44 (4\%) consumed $>20$ drinks/week. In daily smokers, there was a significant correlation between the number of drinks/week and number of cigarettes/day both in men ( $r=$ $0.24, p<0.001)$ and in women $(r=0.16, p<0.001)$.

Smoking and haemoglobin

Haemoglobin concentrations in the entire series are shown in Table 2. In men, there was no significant difference between the age groups $(p=0.08)$. In women, mean haemoglobin displayed a gradual, significant increase with age $(p=0.001)$; mean value in the entire series of women $(n=1,437)$ was $8.58 \pm 0.65$ (SD) $\mathrm{mmol} / \mathrm{L}$, with $95 \% \mathrm{CI}$ $7.31-9.85 \mathrm{mmol} / \mathrm{L}$.
Table 2 also shows the influence of smoking on haemoglobin concentrations. In both genders, smokers had significantly higher mean haemoglobin than non-smokers. In men, the difference in mean haemoglobin was $0.11 \mathrm{mmol} / \mathrm{L}(1.8 \mathrm{~g} / \mathrm{L})$, and in women, it ranged from $0.12 \mathrm{mmol} / \mathrm{L}(1.9 \mathrm{~g} / \mathrm{L})$ in 30 -year-old to $0.31 \mathrm{mmol} / \mathrm{L}$ $(5.0 \mathrm{~g} / \mathrm{L})$ in 50 -year-old women.

The influence of smoking on haemoglobin was evaluated in subjects with serum ferritin $>20 \mu \mathrm{g} / \mathrm{L}(n=2652)$, i.e. without iron deficiency as shown in Table 3. Male smokers had significantly higher mean haemoglobin than non-smokers, being $0.12 \mathrm{mmol} / \mathrm{L}(1.9 \mathrm{~g} / \mathrm{L})$ higher. Thirtyyear-old female smokers had similar haemoglobin as nonsmokers, whereas 40-, 50-, and 60-year-old smokers had significantly higher mean haemoglobin than non-smokers, being $0.19-0.27 \mathrm{mmol} / \mathrm{L}(3.1-4.4 \mathrm{~g} / \mathrm{L})$ higher. We found exactly the same pattern in subjects with serum ferritin $\leq 20 \mu \mathrm{g} / \mathrm{L}(n=288$; data not shown).

There was a weak but significant positive correlation in daily smokers between haemoglobin and the number of cigarettes/day in women $(r=0.12, p=0.002)$ but not in men $(r=0.06, p=0.10)$. Table 4 shows the association in daily smokers between haemoglobin and the number of cigarettes/ day. In all groups, heavy smokers had higher mean haemoglobin levels than "light" smokers (less than or equal to ten cigarettes/day), but the difference was significant only in 30- and 50-year-old women. Men smoking more than ten cigarettes/day had a 1.4\% increase in haemoglobin compared to non-smokers, whereas the increase in women was on the average $3.5 \%(2.7 \%, 3.8 \%, 4.7 \%$, and $2.7 \%$ in $30-, 40-, 50-$, and 60 year-old women, respectively).

Table 5 shows the frequency of low haemoglobin values $<130 \mathrm{~g} / \mathrm{L}(8.07 \mathrm{mmol} / \mathrm{L})$ and of $<120 \mathrm{~g} / \mathrm{L}(7.45 \mathrm{mmol} / \mathrm{L})$ as 
Table 2 Haemoglobin concentrations according smoking habits in the entire series $(n=2,940)$

\begin{tabular}{|c|c|c|c|c|c|}
\hline & \multirow[t]{2}{*}{ Smoking } & \multicolumn{3}{|c|}{ Haemoglobin (mmol/L) } & \multirow[t]{2}{*}{$p$ value } \\
\hline & & Mean \pm SD & Mean 95\% CI & Reference range $95 \% \mathrm{CI}$ & \\
\hline \multicolumn{6}{|l|}{ Men } \\
\hline \multicolumn{6}{|c|}{ Age (years) } \\
\hline \multirow[t]{4}{*}{$30-60$} & Daily & $9.62 \pm 0.70$ & $9.57-9.67$ & $8.25-10.99$ & \multirow{4}{*}{0.006} \\
\hline & Occasionally & $9.65 \pm 0.61$ & $9.48-9.82$ & $8.45-10.85$ & \\
\hline & No & $9.51 \pm 0.64$ & $9.45-9.56$ & $8.26-10.76$ & \\
\hline & All & $9.58 \pm 0.68$ & $9.54-9.61$ & $8.25-10.91$ & \\
\hline \multicolumn{6}{|l|}{ Women } \\
\hline \multicolumn{6}{|c|}{ Age (years) } \\
\hline \multirow[t]{4}{*}{30} & Daily & $8.50 \pm 0.59$ & $8.42-8.58$ & $7.34-9.66$ & \multirow{4}{*}{0.14} \\
\hline & Occasionally & $8.45 \pm 0.52$ & $8.08-8.82$ & $7.43-9.47$ & \\
\hline & No & $8.38 \pm 0.58$ & $8.28-8.47$ & $7.24-9.52$ & \\
\hline & All & $8.45 \pm 0.58$ & $8.39-8.51$ & $7.31-9.59$ & \\
\hline \multirow[t]{4}{*}{40} & Daily & $8.63 \pm 0.65$ & $8.53-8.73$ & $7.36-9.90$ & \multirow{4}{*}{0.0001} \\
\hline & Occasionally & $8.28 \pm 0.62$ & $7.95-8.61$ & $7.07-9.50$ & \\
\hline & No & $8.36 \pm 0.57$ & $8.28-8.44$ & $7.24-9.48$ & \\
\hline & All & $8.48 \pm 0.62$ & $8.41-8.54$ & $7.27-9.70$ & \\
\hline \multirow[t]{4}{*}{50} & Daily & $8.80 \pm 0.71$ & $8.70-8.90$ & $7.41-10.19$ & \multirow{4}{*}{0.0001} \\
\hline & Occasionally & $8.78 \pm 0.40$ & $8.52-9.03$ & $8.00-9.56$ & \\
\hline & No & $8.49 \pm 0.70$ & $8.38-8.60$ & $7.12-9.86$ & \\
\hline & All & $8.67 \pm 0.71$ & $8.60-8.75$ & $7.28-10.06$ & \\
\hline \multirow[t]{4}{*}{60} & Daily & $8.86 \pm 0.65$ & $8.75-8.98$ & $7.59-10.13$ & \multirow{4}{*}{0.003} \\
\hline & Occasionally & $8.43 \pm 0.68$ & $8.07-8.79$ & $7.10-9.76$ & \\
\hline & No & $8.66 \pm 0.60$ & $8.57-8.75$ & $7.48-9.84$ & \\
\hline & All & $8.73 \pm 0.63$ & $8.66-8.80$ & $7.50-9.97$ & \\
\hline
\end{tabular}

${ }^{\mathrm{a}}$ ANOVA

defined by the World Health Organization's cutoff values for anaemia in men and women, respectively [11]. In men, the frequency of low haemoglobin was similar $(2.1 \%)$ in smokers and non-smokers. However, among women, nonsmokers had a consistently higher frequency of low haemoglobin values (4.4-6.7\% according to age) than smokers $(0.8-3.6 \%$ according to age). In the entire series, the frequency of low haemoglobin was significantly higher in female non-smokers $(5.4 \%)$ than in smokers $(2.5 \%)$ $(p<0.001)$.

\section{Alcohol and haemoglobin}

We evaluated the effect of alcohol separately in nonsmokers and in daily smokers. In non-smokers, there was a significant positive correlation between the number of drinks/week and haemoglobin levels both in men $(r=0.14$, $p=0.001)$ and in women $(r=0.08, p=0.05)$. The effect of alcohol was only present in subjects consuming $>14$ drinks/ week. It appears from Table 6 that male non-smokers consuming $>14 \mathrm{drinks} /$ week have $1.3 \%$ higher mean haemoglobin than non-smokers consuming $\leq 14$ drinks/ week $(p=0.04)$. In smoking men taking $>14$ drinks/week, mean haemoglobin was $1.5 \%$ higher than in men taking $\leq 14$ drinks/week. Similar results were found in female non-smokers, where heavy drinkers had on the average $1.9 \%(3.7 \%, 1.6 \%, 0 \%$ and $2.4 \%$ according to age group) higher mean haemoglobin than light drinkers, while heavy-drinking female smokers had on the average $2.3 \%$ (3.3\%, 2.0\%, $1.7 \%$, and $2.3 \%$ according to age group) higher mean haemoglobin than light-drinking female smokers.

In daily smokers, there were likewise a significant positive correlation between the number of drinks/week and haemoglobin levels both in men $(r=0.11, p=0.001)$ and in women $(r=0.12, p=0.001)$.

Smoking and alcohol vs serum ferritin

There was no consistent association between smoking and serum ferritin. Male smokers had significantly lower ferritin than non-smokers $(p=0.002)$, while female smokers had higher ferritin than non-smokers, although the difference was significant only in 40-year-old women $(p=0.01)$.

However, there was a consistent positive correlation between ferritin and alcohol consumption both in men $(r=$ $0.20, p<0001)$ and in women $(r=0.15, p<0.001)$. 
Table 3 Haemoglobin concentrations according smoking habits in subjects with serum ferritin $>20 \mu \mathrm{g} / \mathrm{L}(n=2,652)$

\begin{tabular}{|c|c|c|c|c|c|}
\hline & \multirow[t]{2}{*}{ Smoking, $n$} & \multicolumn{3}{|c|}{ Haemoglobin, mmol/L } & \multirow[t]{2}{*}{$p$ value } \\
\hline & & mean $\pm \mathrm{SD}$ & mean $95 \% \mathrm{CI}$ & reference range $95 \% \mathrm{CI}$ & \\
\hline \multicolumn{6}{|l|}{ Men } \\
\hline \multicolumn{6}{|c|}{ Age (years) } \\
\hline \multirow[t]{3}{*}{$30-60$} & 868 daily & $9.63 \pm 0.69$ & $9.59-9.68$ & $8.28-10.98$ & \multirow{3}{*}{0.003} \\
\hline & 51 occasionally & $9.65 \pm 0.61$ & $9.48-9.82$ & $8.45-10.85$ & \\
\hline & 552 no & $9.51 \pm 0.62$ & $9.46-9.56$ & $8.26-10.76$ & \\
\hline \multicolumn{6}{|l|}{ Women } \\
\hline \multicolumn{6}{|c|}{ Age (years) } \\
\hline \multirow[t]{3}{*}{30} & 177 daily & $8.51 \pm 0.59$ & $8.42-8.56$ & $7.35-9.67$ & \multirow{3}{*}{0.9} \\
\hline & 10 occasionally & $8.45 \pm 0.52$ & $8.08-8.82$ & $7.43-9.47$ & \\
\hline & 104 no & $8.50 \pm 0.54$ & $8.39-8.60$ & $7.44-9.56$ & \\
\hline \multirow[t]{3}{*}{40} & 136 daily & $8.68 \pm 0.64$ & $8.60-8.79$ & $7.43-9.93$ & \multirow{3}{*}{0.001} \\
\hline & 12 occasionally & $8.43 \pm 0.42$ & $8.16-8.69$ & $7.61-9.25$ & \\
\hline & 133 no & $8.44 \pm 0.44$ & $8.37-8.52$ & $7.58-9.30$ & \\
\hline \multirow[t]{3}{*}{50} & 161 daily & $8.89 \pm 0.68$ & $8.79-8.99$ & $7.56-10.22$ & \multirow{3}{*}{0.002} \\
\hline & 10 occasionally & $8.75 \pm 0.40$ & $8.47-9.03$ & $8.00-9.53$ & \\
\hline & 121 no & $8.61 \pm 0.59$ & $8.50-8.71$ & $7.58-9.30$ & \\
\hline \multirow[t]{3}{*}{60} & 127 daily & $8.85 \pm 0.64$ & $8.74-8.97$ & $7.60-10.10$ & \multirow{3}{*}{0.005} \\
\hline & 16 occasionally & $8.43 \pm 0.68$ & $8.07-8.79$ & $7.10-9.76$ & \\
\hline & 174 no & $8.66 \pm 0.60$ & $8.57-8.75$ & $7.48-9.84$ & \\
\hline
\end{tabular}

${ }^{\mathrm{a}}$ ANOVA

BMI vs haemoglobin, smoking and alcohol

Men had a mean BMI of $27 \pm 4$ (SD) and women of $25 \pm 5$ $(p<0.0001)$. In non-smoking men having $\leq 14 \mathrm{drinks} /$ week $(n=162)$, there was no significant correlation between BMI and haemoglobin $(r=0.11, p=0.2)$. Likewise, in nonsmoking women having less than or equal to seven drinks/week $(n=60)$, there was no correlation between BMI and haemoglobin $(r=-0.006, p=1.0)$.
Men $(n=1,503)$ displayed a weak correlation between BMI and haemoglobin $(r=0.14, p=0.01)$. Women displayed no correlations in the four age groups (data not shown).

In men, there was a significant correlation between BMI and the daily number of smoked cigarettes $(r=0.16, p=$ $0.01)$ as well as the weekly number of drinks $(r=0.08, p=$ $0.01)$. Such correlations were not found in women either for cigarettes $(r=0.04, p=0.4)$ or for drinks $(r=-0.003, p=0.9)$.

Table 4 Association between number of cigarettes and haemoglobin in daily cigarette smokers

\begin{tabular}{lccc}
\hline & Cigarettes no./day & Subjects $n$ & ${\text { Haemoglobin }(\mathrm{mmol} / \mathrm{L})^{\mathrm{a}}}$ \\
\hline Men & & & \\
Age (years) & & & \\
$30-60$ & $\leq 10$ & 203 & $9.60 \pm 0.66$ \\
& $>10$ & 507 & $9.64 \pm 0.74$ \\
Women & & & \\
Age (years) & $\leq 10$ & 72 & $8.28 \pm 0.59$ \\
30 & $>10$ & 147 & $8.61 \pm 0.56$ \\
& $\leq 10$ & 57 & $8.57 \pm 0.46$ \\
40 & $>10$ & 107 & $8.68 \pm 0.71$ \\
50 & $\leq 10$ & 60 & $8.60 \pm 0.57$ \\
60 & $>10$ & 61 & $8.89 \pm 0.72$ \\
& $\leq 10$ & 46 & $8.73 \pm 0.62$ \\
\end{tabular}

${ }^{\mathrm{a}} \mathrm{Mean} \pm \mathrm{SD}$

b Student's $t$ test 
Table 5 Association between smoking/non-smoking and the frequency of low haemoglobin values as defined by the World Health Organization's cutoff values for anaemia [11]

\begin{tabular}{|c|c|c|c|c|}
\hline & Smoking & Subjects $n$ & Low haemoglobin, $n(\%)$ & $p$ value \\
\hline \multicolumn{5}{|l|}{$\operatorname{Men}^{\mathrm{a}}$} \\
\hline \multicolumn{5}{|c|}{ Age (years) } \\
\hline \multirow[t]{2}{*}{$30-60$} & Daily & 892 & $19(2.1)$ & 0.9 \\
\hline & No & 560 & $12(2.1)$ & \\
\hline \multicolumn{5}{|c|}{ Women $^{\mathrm{a}}$} \\
\hline \multicolumn{5}{|c|}{ Age (years) } \\
\hline \multirow[t]{2}{*}{30} & Daily & 223 & $8(3.6)$ & 0.3 \\
\hline & No & 148 & $9(6.1)$ & \\
\hline \multirow[t]{2}{*}{40} & Daily & 169 & $4(2.4)$ & 0.2 \\
\hline & No & 190 & $9(4.7)$ & \\
\hline \multirow[t]{2}{*}{50} & Daily & 196 & $5(2.6)$ & 0.06 \\
\hline & No & 149 & $10(6.7)$ & \\
\hline \multirow[t]{2}{*}{60} & Daily & 128 & $1(0.8)$ & 0.06 \\
\hline & No & 180 & $8(4.4)$ & \\
\hline
\end{tabular}

${ }^{\mathrm{a}}$ Cut-off value men: $<130 \mathrm{~g} / \mathrm{L}(8.07 \mathrm{mmol} / \mathrm{L})$; women: $<120 \mathrm{~g} / \mathrm{L}(7.45 \mathrm{mmol} / \mathrm{L})$

${ }^{\mathrm{b}}$ Pearson's chi-square test

\section{Discussion}

Although the number of smokers is steadily declining in Denmark, smoking is still widespread among the population. According to a Danish survey in 2003, 30\% of men and $24 \%$ of women are daily smokers, and the fraction of hardcore heavy smokers has increased (http://www.sst.dk). Our results demonstrate that smoking has a significant impact on haemoglobin concentrations, irrespective of gender and age. Smokers had consistently higher haemoglobin levels than non-smokers, and the increase in haemoglobin displayed a positive correlation with the

Table 6 Association between haemoglobin and consumption of alcohol in non-smokers and daily smokers

\begin{tabular}{|c|c|c|c|c|c|}
\hline & Smoking & Alcohol drinks/week & & Haemoglobin $(\mathrm{mmol} / \mathrm{L})$ & $p$ value $^{\mathrm{a}}$ \\
\hline Men & & $\leq 14$ & $>14$ & & \\
\hline \multicolumn{6}{|l|}{ Age (years) } \\
\hline \multirow[t]{4}{*}{$30-60$} & No & 364 & & $9.48 \pm 0.62$ & 0.04 \\
\hline & No & & 146 & $9.60 \pm 0.63$ & \\
\hline & Daily & 502 & & $9.56 \pm 0.70$ & 0.004 \\
\hline & Daily & & 327 & $9.70 \pm 0.72$ & \\
\hline Women & & $\leq 7$ & $>7$ & & \\
\hline \multicolumn{6}{|l|}{ Age (years) } \\
\hline \multirow[t]{4}{*}{30} & No & 98 & & $8.33 \pm 0.57$ & 0.03 \\
\hline & No & & 18 & $8.64 \pm 0.44$ & \\
\hline & Daily & 127 & & $8.42 \pm 0.58$ & 0.003 \\
\hline & Daily & & 56 & $8.70 \pm 0.58$ & \\
\hline \multirow[t]{4}{*}{40} & No & 124 & & $8.35 \pm 0.58$ & 0.24 \\
\hline & No & & 30 & $8.48 \pm 0.41$ & \\
\hline & Daily & 81 & & $8.60 \pm 0.70$ & 0.14 \\
\hline & Daily & & 54 & $8.77 \pm 0.61$ & \\
\hline \multirow[t]{4}{*}{50} & No & 87 & & $8.60 \pm 0.55$ & 0.52 \\
\hline & No & & 23 & $8.51 \pm 0.75$ & \\
\hline & Daily & 98 & & $8.74 \pm 0.61$ & 0.16 \\
\hline & Daily & & 59 & $8.89 \pm 0.70$ & \\
\hline \multirow[t]{4}{*}{60} & No & 92 & & $8.62 \pm 0.59$ & 0.12 \\
\hline & No & & 25 & $8.83 \pm 0.55$ & \\
\hline & Daily & 76 & & $8.84 \pm 0.68$ & 0.20 \\
\hline & Daily & & 25 & $9.04 \pm 0.64$ & \\
\hline
\end{tabular}

${ }^{\text {a }}$ Student's $t$ test 
number of cigarettes/day in women. This correlation was not significant in men, perhaps due to other confounding factors including alcohol consumption and BMI. In heavy smokers, the increase in haemoglobin was higher in women, i.e. $\sim 0.39 \mathrm{mmol} / \mathrm{L}(6.3 \mathrm{~g} / \mathrm{L})$ than $0.19 \mathrm{mmol} / \mathrm{L}$ $(3.1 \mathrm{~g} / \mathrm{L})$ in men compared to non-smokers.

In addition, we found that the amount of alcohol per se had a significant influence on haemoglobin levels in both genders, when it exceeded 14 drinks/week, i.e. $\sim 170 \mathrm{~g}$ ethanol/week in men, and seven drinks/week, i.e. $\sim 85 \mathrm{~g}$ ethanol/week, in women. The impact of alcohol on haemoglobin was more pronounced in women than in men. In both smokers and non-smokers, the quantitative alcohol consumption displayed a positive correlation with haemoglobin. Furthermore, there was a positive correlation between alcohol consumption and serum ferritin levels. This could be due to an enhancing effect on dietary iron absorption [12], which tends to improve iron status and lower the risk of iron deficiency. In addition, alcohol has a harmful effect on the hepatocytes and may induce an inappropriate release of intracellular ferritin to the plasma [13].

Actually, the effect of alcohol on haemoglobin appeared to be of the same order of magnitude as the effect of tobacco. However, the number of cigarettes/day displayed a positive correlation with the number of drinks/week, demonstrating that tobacco and alcohol go hand in hand as lifestyle factor companions. This makes it difficult to separate the effect of tobacco from the effect alcohol. Approximately $90 \%$ of men and $80 \%$ of women consumed alcohol, including the vast majority of smokers.

Other studies have reported the influence of smoking on haemoglobin levels. Tsang et al. [6] examined 3,654 Australian subjects 49-97 years of age and stated that smoking and alcohol influenced the reference range but did not report any specific details. In a Dutch cohort study of 16,254 subjects 20-70 years of age, Van Tiel et al. [8] found higher haemoglobin in smokers than in non-smokers of both genders. Skjelbakken et al. [7] examined a cohort of 4,159 Norwegian men 20-49 years of age at baseline and 20 years later. They observed no difference in mean haemoglobin levels after 20 years in any strata of age, which is in accordance with our results showing similar haemoglobin levels in men from 30 to 60 years of age. During the 20 -year period, $20 \%$ of the men had quitted smoking. Smoking cessation lowered their mean haemoglobin by $0.10 \mathrm{mmol} / \mathrm{L}(1.6 \mathrm{~g} / \mathrm{L})$ compared to those who never smoked. Furthermore, among consistent smokers, there was a positive dose-response relationship between change in cigarettes smoked per day and change in haemoglobin. Nordin et al. [3] established haematological reference intervals in the Nordic Reference Interval Project comprising 1,826 subjects (866 men) 18-90 years of age, of whom $14 \%$ were regular smokers. Haemoglobin decreased with age in men; this was probably due to the large age variation with inclusion of elderly men. In previous studies [2], we have also demonstrated a decrease in haemoglobin in men above 60 years of age. Haemoglobin increased with age in women [3], which is consistent with our findings. Smoking increased the mean haemoglobin in women by $0.25 \mathrm{mmol} / \mathrm{L}(4.0 \mathrm{~g} / \mathrm{L})$, but there was no increase in men [3]. There was no effect of alcohol on haemoglobin levels [3]. The distribution of haemoglobin in smoking vs nonsmoking women fulfilled the criteria for partitioning. However, for practical reasons, in the final calculation of the reference values, only gender and age were considered when applying the rules for partitioning [3]. Milman et al. [2] examined 358 Danes 80 years of age, of whom $\sim 30 \%$ were daily smokers. Male smokers had higher median haemoglobin than non-smokers ( 8.59 vs $8.56 \mathrm{mmol} / \mathrm{L})$; likewise, female smokers had higher median haemoglobin than non-smokers ( 8.38 vs $8.07 \mathrm{mmol} / \mathrm{L})$.

It appear from both the present and previous series $[2,7]$ that female smokers display a higher percent increase in mean haemoglobin than male smokers. This could indicate a higher sensitivity to the CO-induced hypoxaemic stimulus and consequently a greater erythropoietic response. However, we were not able to adjust for contributing factors in women, e.g. the concentration of carboxyhaemoglobin, the exact number of cigarettes/day and whether the smoke was inhaled or not.

Tobacco smoking increases the blood levels of CO [14], which binds to haemoglobin to form carboxyhaemoglobin, which is unable to bind oxygen. The blood concentration of carboxyhaemoglobin increases in proportion with the amount of smoked tobacco and whether the smoke is inhaled. The higher the carboxyhaemoglobin levels, the lower the oxygen transporting capacity of the haemoglobin mass, a scenario corresponding to functional anaemia, which can reduce exercise tolerance and maximal aerobic capacity [15]. Rats being exposed to CO display an increase in both the blood reticulocyte count and the haemoglobin concentration; when exposure is stopped, haematological parameters return to pre-exposure levels [16].

Presumably, the reduced oxyhaemoglobin levels in smokers stimulate the production of erythropoietin, which increases the haemoglobin concentrations. In our series, men smoking $>10$ cigarettes/day had a $1.4 \%$ increase in haemoglobin compared to non-smokers, whereas in women, the increase was on the average $3.5 \%$, which is in accordance with the carboxyhaemoglobin levels of 3-6\% reported in smokers [14, 17]. "Normalization" of haemoglobin after smoking cessation has likewise been reported in humans $[7,8]$.

However, besides carboxyhaemoglobin, we should also consider that other yet unidentified compounds in the 
complex chemistry of tobacco smoke may have direct or indirect influence on erythropoiesis.

Apparently, the influence of BMI on haemoglobin levels was small. In non-smokers/non-drinkers, there was no association between BMI and haemoglobin in either of the genders. Therefore, the weak association between BMI and haemoglobin observed in the entire male series appears to be indirect, i.e. elicited by the association between BMI and smoking and drinking. This association was not found in women.

In the clinical setting, we already operate with differential reference ranges for haemoglobin according to age and gender. Should we also adjust the reference range according to smoking and alcohol consumption? If we use a reference range derived from a mixed population of smokers and nonsmokers, a fraction of non-smokers will erroneously be classified as being anaemic and a fraction of smokers will erroneously be classified as not having anaemia. For example, in our series, the frequency of low haemoglobin values $<120 \mathrm{~g} / \mathrm{L}$ was more than twice as high in female non-smokers $(5.4 \%)$ than in smokers $(2.5 \%)$. The number of subjects who will be misclassified depends on the ratio between smokers/ non-smokers in the background population. A high ratio will increase the number of misclassified non-smokers and a low ratio will increase the number of misclassified smokers. Ideally, smokers and non-smokers should have separate reference ranges for haemoglobin, although this would be of some inconvenience in the daily clinical routine.

In conclusion, tobacco smoking has an increasing effect on haemoglobin concentrations, which is proportional to the amount of tobacco smoked, and appears to be more pronounced in women. Likewise, high alcohol consumption has an increasing effect on haemoglobin in both genders, being most pronounced in women. However, in many patients, it is difficult or impossible to obtain reliable estimates of both tobacco and alcohol intake. Therefore, in clinical biochemistry and laboratory medicine, the relatively small changes in haemoglobin do not justify the use of separate reference ranges for in smokers and alcohol consumers.

Acknowledgements The study was supported by Sygekassernes Helsefond (grant H 11-23-89), Forskningsfonden for Medicinsk Forskning i København, Færøerne og Grønland (grant 46-83), Bloddonorernes Forskningsfond and Danish National Board of Health. The authors are indebted to the Department of Clinical Biochemistry, Bispebjerg Hospital, Copenhagen, Denmark, for analyses of haemoglobin and serum ferritin.

\section{References}

1. Skjelbakken T, Wilsgaard T, Førde OH, Arnesen E, Løchen ML (2006) Haemoglobin predicts total mortality in a general young and middle-aged male population. The Tromsø Study. Scand J Clin Lab Invest 66:567-576 doi:10.1080/00365510600863895

2. Milman N, Pedersen AN, Ovesen L, Schroll M (2008) Haemoglobin concentrations in 358 apparently healthy 80 -year-old Danish men and women. Should the reference interval be adjusted for age? Aging Clin Exp Res 20:8-14

3. Nordin G, Mårtensson A, Swolin B et al (2004) A multicentre study of reference intervals for haemoglobin, basic blood cell counts and erythrocyte indices in the adult population of the Nordic countries. Scand J Clin Lab 64:385-398 doi:10.1080/ 00365510410002797

4. Milman N, Kirchhoff M (1991) Iron stores in 1433, 30- to 60-yearold Danish males. Evaluation by serum ferritin and haemoglobin. Scand J Clin Lab 51:635-641 doi:10.3109/00365519109104574

5. Milman N, Kirchhoff M (1992) Iron stores in 1359, 30- to 60year-old Danish women: evaluation by serum ferritin and hemoglobin. Ann Hematol 64:22-27 doi:10.1007/BF01811467

6. Tsang CW, Lazarus R, Smith W, Mitchell P, Koutts J, Burnett L (1998) Hematological indices in an older population sample: derivation of healthy reference values. Clin Chem 44:96-101

7. Skjelbakken T, Dahl IM, Wilsgaard T, Langbakk B, Løchen ML (2006) Changes in haemoglobin levels according to changes in body mass index and smoking habits, a 20 -year follow-up of a male cohort: the Tromsø Study 1974-1995. Eur J Epidemiol 21:493-499 doi:10.1007/s10654-006-9032-y

8. Van Tiel E, Peeters PH, Smit HA et al (2002) Quitting smoking may restore hematological characteristics within five years. Ann Epidemiol 12:378-388 doi:10.1016/S1047-2797(01)00282-4

9. Nordic Council of Ministers Nordic Nutrition Recommendations (2004) Copenhagen 2004

10. Milman N, Pedersen NS, Visfeldt J (1983) Serum ferritin in healthy Danes: relation to bone marrow haemosiderin iron. Dan Med Bull 30:115-120

11. World Health Organization (2001) Iron deficiency anaemia. Assessment, prevention and control. WHO/NHD/01.3, Geneva

12. Charlton RW, Jacobs P, Seftel H, Bothwell TH (1964) The effect of alcohol on iron absorption. BMJ 5422:1427-1429

13. Tavill AS, Quadri AM (2004) Alcohol and iron. Semin Liver Dis 24:317-325 doi:10.1055/s-2004-832943

14. Scherer G (2006) Carboxyhemoglobin and thiocyanate as biomarkers of exposure to carbon monoxide and hydrogen cyanide in tobacco smoke. Exp Toxicol Pathol 58:101-124 doi:10.1016/j. etp.2006.07.001

15. McDonough P, Moffatt RJ (1999) Smoking-induced elevations in blood carboxyhaemoglobin levels. Effect on maximal oxygen uptake. Sports Med 27:275-283 doi:10.2165/00007256-199927050-00001

16. Ramsey JM (1975) The hematological effects of chronic, low level exposures to carbon monoxide in rats. Bull Environ Contam Toxicol 13:537-542 doi:10.1007/BF01685176

17. Cronenberger C, Mould DR, Roethig H-J, Sarkar M (2008) Population pharmacokinetic analysis of carboxyhaemoglobin concentrations in adult cigarette smokers. Br J Clin Pharmacol 65:30-39 doi: $10.1111 / j .1365-2125.2007 .02974 . x$ 